\title{
RING-LIKE CORNEAL DEPOSITS IN A CASE OF CONGENITAL SPHEROCYTOSIS*
}

\author{
BY \\ R. DALGLEISH \\ University Department of Ophthalmology, Manchester Royal Eye Hospital
}

IT is the purpose of this paper to present details of a case of congenital spherocytosis (congenital haemolytic jaundice) in which bilateral ring-like corneal deposits produced visual symptoms. This ocular complication does not appear to have been previously reported.

\section{Case Report}

A girl aged 14 years was first seen at a local hospital on August 5, 1961. She had been ill for about 4 days with pyrexia, pallor, jaundice, and pain in the splenic region. She had had recurrent attacks of a similar nature since the age of 6 years.

The spleen was enlarged reaching about two fingers below the costal margin, and there was a number of palpable shotty glands in the neck and groins.

Haemoglobin 5.3 g./100 ml. (37 per cent.); colour index 1.0 ; white cell count $6,000 / \mathrm{ml}$; reticulocyte count 5.8 per cent. Many spherocytes seen in the blood film. Direct Coombs's test negative. Serum bilirubin $1.8 \mathrm{mg}$. $/ 100 \mathrm{ml}$., but other liver function tests normal.

The sternal marrow showed active erythropoiesis consistent with a haemolytic anaemia. A urobilinogen test on the urine gave a moderately strong positive reaction.

The blood of the patient's two sisters, parents, and maternal grandmother showed no anaemia, reticulocytosis, spherocytosis, or increased fragility.

A diagnosis of congenital spherocytosis was considered, but the absence of family affection and the presence of enlarged glands were anomalous.

Immediate treatment consisted of a transfusion of 2 pints of blood, a course of systemic tetracycline, and systemic steroids (starting with prednisolone $10 \mathrm{mg}$. three times a day) reducing to $5 \mathrm{mg}$. on the second day, and thereafter maintained at $5 \mathrm{mg}$. twice daily.

The patient was referred to the department of haematology of the Manchester Royal Infirmary and was admitted to hospital on May 10, 1962, for investigation and treatment. At that time, she stated that her vision had been slightly blurred for about 3 weeks. This was particularly troublesome when reading, as the extremities of the letters appeared indistinct.

Examination.-The visual acuity was $6 / 5$ in each eye. There were bilateral ring-like corneal opacities (Figure, opposite). These were oval or flattened, with the long axes horizontal, and were situated slightly below and lateral to the centre of the cornea, right more than left. Slit-lamp microscopy showed that the opacities consisted of an aggregation of very fine reddish-brown granular deposits situated in the deeper layers of the corneal epithelium. The internal margin of each ring-like opacity was relatively clear-cut, whereas the density of the fine granular deposits decreased less steeply at the peripheral margin, and one had the impression that the deposits were proceeding from the limbus towards the central rings. Apart from the corneae, the optic media were clear, and the fundi were normal.

At this time, the patient was neither pale nor jaundiced, and the spleen was not palpable. Haemoglobin 13.7 g. $/ 100 \mathrm{ml}$. (94 per cent.); red cells 4,580,000/ml., reticulocytes 22.4 per cent. Blood film showed many spherocytes and a polymorph leucocytosis. Fragility of red cells grossly excessive. Bone-marrow showed intense normoblastic activity. Serum iron $140 \mathrm{mg}$./100 ml. Direct

* Received for publication April 20, 1964. 


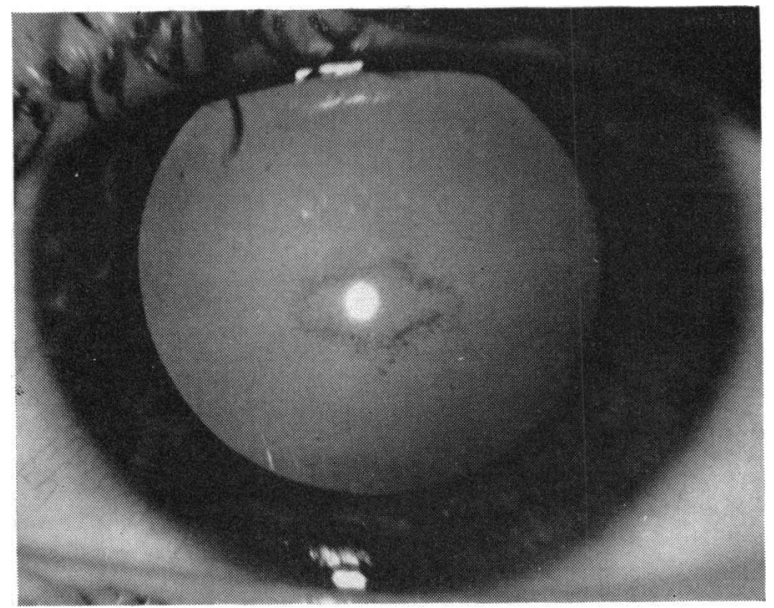

FIGURE.-Left eye, showing ring-like corneal opacity.

Coombs's test negative. Schumm's test negative. The patient's red cells had a much reduced survival time in her own and in a normal person's blood ( $\mathrm{T} \frac{1}{2} 10$ days). Treatment with prednisolone was stopped, since the diagnosis of congenital spherocytosis was now established.

Operation.-Splenectomy was performed under hydrocortisone cover on May 23, 1962.

The spleen was large ( $360 \mathrm{~g}$.) and the histology was typical of that found in spherocytosis, overfilling of the pulp with red cells and compression of the Malpighian bodies. The patient made an uneventful recovery from the operation.

Result.-Post-operatively the visual symptoms rapidly disappeared, and 3 months later slitlamp microscopy showed that the corneae were completely clear.

\section{Discussion}

Gass (1964) draws attention to the similarity of the clinical appearance of the corneal pigmentation in Fleischer's ring (Fleischer, 1906), the Hudson-Stähli line (Hudson, 1911; Stähli, 1918), Stocker's line (Stocker and Prindle, 1939), and the pigmentation associated with superficial corneal scars. In addition, he has presented conclusive evidence indicating that these linear corneal opacities are produced as a result of the intra-cytoplasmic deposition of iron in the deeper layers of the corneal epithelium. He has named these conditions "the iron lines of the superficial cornea". It must be remembered that Fleischer, Stähli, and Stocker, and also Busacca (1952) all demonstrated iron in certain of these superficial opacities.

Both in colour and in linear intra-epithelial distribution, the ring-like corneal deposits seen in this case of congenital spherocytosis closely resemble the opacities referred to in the previous paragraph. These deposits developed during the stage of active haemolysis and haemosiderosis, and resolved when the haemolysis was arrested by splenectomy. In view of these facts, it is suggested that the ring-like opacities were produced as a result of the intra-epithelial deposition of the excess free iron. The possible supplementary effect of the systemic prednisolone that was administered in the pre-operative stage must also be borne in mind.

In the 2 years that have elapsed since this patient was seen, we have not seen a zimilar case, and it is hoped that this report will widen the search. 


\section{Summary}

A case is described of congenital spherocytosis in which bilateral ring-like corneal opacities produced visual symptoms.

Although histochemical proof is lacking, it is suggested that these opacities were caused by the intra-epithelial deposition of excess free iron, and that this case may be added to the group of conditions described by Gass (1964) as "the iron lines of the superficial cornea".

I wish to thank Dr. M. C. G. Israels, Director of the Department of Haematology at the Manchester Royal Infirmary, for permission to publish this case, and for assistance with the presentation of the haematological data.

\section{REFERENCES}

BusAcCA, A. (1952). "Biomicroscopie et histopathologie de l'oeil", vol. 1 (French trans.). Grune and Stratton, New York.

FleisCHER, B. (1906). Münch. med. Wschr., 53, 625.

GaSs, J. D. M. (1964). Arch. Ophthal., 71, 348.

Hudson, A. C. (1911). Roy. Lond. ophthal. Hosp. Rep., 18, 198.

STÄHLI, J. (1918). Klin. Mbl. Augenheilk., 60, 721.

Stocker, F. W., and Prindle, R. E. (1944). Amer. J. Ophthal., 27, 341. 